\title{
Os rosários precederam os coturnos: o anticomunismo nas Cruzadas do Rosário em Família na América Latina e os golpes civil-militares (1960-1964)
}

\author{
Rosaries preceded coturnas: anti-communism in the Family Rosary Crusades in Latin \\ America and civil-military coups (1960-1964)
}

Anderson Jose Guisolphi ${ }^{1}$

\begin{abstract}
RESUMO: O artigo analisa as Cruzadas do Rosário Família como ações anticomunistas nos meios católicos. No Brasil, os eventos foram realizados entre 1962 e 1965, antes e depois do golpe civil-militar de 1964. Analisamos o itinerário do Padre Patrick Peyton, fundador das Cruzadas do Rosário em Família, caracterizado pela oração do rosário associada a grandes astros e estrelas do cinema e a divulgação da oração como arma no combate ao comunismo nos anos da Guerra Fria. O auge do movimento ocorreu entre 1959 e 1985, período da suposta ameaça comunista, especialmente sobre os países latinoamericanos. Há indícios de aproximações de Patrick Peyton com o governo dos EUA no período, e patrocínio da CIA para as jornadas na América Latina, especialmente a partir de 1959. O artigo é parte da dissertação de mestrado em História, defendida pelo autor no PPGH da Universidade de Passo Fundo em 2013. A metodologia empregada foi, sobretudo, o uso de periódicos, cartas e outros documentos dos arquivos da congregação interpretados sob os esforços da análise do discurso.
\end{abstract}

PALAVRAS-CHAVE: anticomunismo, guerra-fria, golpe civil-militar, catolicismo e ditadura.

\begin{abstract}
The article analyzes the Rosary Family Crusades as anti-communist actions in Catholic circles. In Brazil, the events were held between 1962 and 1965, before and after the 1964 civil-military coup. We analyzed the itinerary of Father Patrick Peyton, founder of the Family Rosary Crusades, characterized by the prayer of the rosary associated with great stars and stars cinema and the spread of prayer as a weapon in the fight against communism in the Cold War years. The peak of the movement occurred between 1959 and 1985, a period of the supposed communist threat, especially in Latin American countries. There are indications of Patrick Peyton's approximations with the US government in the period, and sponsorship by the CIA for the journeys in Latin America, especially after 1959. The article is part of the master's dissertation in History, defended by the author at the PPGH of the University de Passo Fundo in 2013. The methodology used was, above all, the use of periodicals, letters and other documents from the congregation's archives interpreted under the efforts of discourse analysis.
\end{abstract}

\footnotetext{
${ }^{1}$ Doutorando em História (UPF). Mestre em História - UPF (2013). Licenciatura em História - UNOESC (2002). Especialização em ARQUEOLOGIA pela Universidade Regional do Alto Uruguai e das Missões (2004). Atualmente é docente no curso de Arquitetura - Unoesc, atuando nos componentes de Patrimônio Histórico e História das Cidades. Docente no curso de Arquitetura Uceff. É também servidor na UFFS Técnico em Assuntos Educacionais na UFFS. E-mail: hystoriander@hotmail.com
} 
Key-words: anti-communism, cold war, civil-military coup, Catholicism and dictatorship.

\section{Introdução}

O presente artigo é parte da dissertação de mestrado acerca dos eventos chamados Cruzadas do Rosário em Família, ações anticomunistas nos meios católicos, especialmente em países latino-americanos, na década de 1960. O recorte para este artigo apresenta o que foram as Cruzadas do Rosário, qual a sua origem, as características de seu fundador, o padre Patrick Peyton, e a sua aproximação com o discurso anticomunista. Tais Cruzadas foram fundadas na década de 1940, realizadas inicialmente nos EUA e Canadá, posteriormente foram alvo de grandes campanhas na América Latina - a partir de 1959, no Chile, e no Brasil, entre 1962 e 1964.

Diante do panorama latino-americano de transformação política, em meados do século XX, e da perspectiva religiosa de compromisso ético com a transformação das estruturas de dominação e superação das desigualdades sociais, atuaram grupos contrários a esse modo de pensar e de agir. Dessa maneira, este estudo demonstra as ações das Cruzadas do Rosário em Família como ações anticomunistas nos meios católicos brasileiros, entre 1962 e 1964. Em particular, buscamos indícios de anticomunismo nas ações do padre Patrick Peyton, fundador e organizador das Cruzadas do Rosário em Família no Brasil, nos anos que antecederam e sucederam o golpe civil-militar em 1964.

Entre as fontes utilizadas, destacamos as publicações $A$ man of faith (Um homem de fé), de 1983, e All for her (Tudo por Ela), de 1967, respectivamente, biografia e autobiografia do clérigo. Utilizamos também parte da correspondência trocada entre os Papas Paulo VI, Pio XII e o padre Patrick Peyton, e, também, outros documentos oficiais da Igreja Católica, bem como fotografias do acervo das Cruzadas do Rosário. Embora o caráter das fontes aponte hermetismo e unilateralidade, por serem produzidas pelo próprio movimento, buscamos nelas indícios de anticomunismo que nos ajudem a responder à problemática proposta. Essas fontes nos foram disponibilizadas pela Congregação de Santa Cruz, na qual congregou Patrick Peyton. Dessa maneira, certamente representantes da congregação selecionaram quais documentos poderiam ser disponibilizados à pesquisa e, outros, certamente foram retidos. Por exemplo, faltaram documentos que 
comprovassem a provisão de dinheiro por parte da Agência de Inteligência Americana (CIA, do original Central Intelligence Agency) ao empreendimento. No entanto, fizemos tal interpretação com base em outros indícios, tais como a reprimenda do Papa, em carta, ao padre Peyton, para que não utilizasse mais de recursos financeiros da CIA. São fontes herméticas, com linguagem específica e direcionada para fins religiosos e, portanto, opacas quanto aos indícios de anticomunismo que buscamos evidenciar nelas; mas que, com método e parcimônia, fizemos delas verter interpretações qualitativas.

Por "anticomunismo", entendemos o discurso sobre a ameaça que os comunistas representavam para a humanidade e para o Cristianismo. Nesse sentido, Marco Antônio M. L. Pereira (2010) analisa as origens do anticomunismo católico no Brasil, trazendo elementos para a discussão acerca das representações sobre os inimigos da Igreja, entre eles, o Comunismo, visto como o perigo maior pela Igreja Católica. O autor disserta acerca da fundação da revista $A$ ordem, em 1921, que agrupava uma elite intelectual católica laica a partir de Jackson de Figueiredo e do Centro Dom Vital. Tal revista foi um dos principais veículos de divulgação do pensamento conservador católico na época. $\mathrm{O}$ Centro Dom Vital e a revista $A$ ordem representaram uma tentativa de retomada da influência do pensamento católico entre os intelectuais no Brasil.

A temática anticomunista constitui uma linha investigativa que tem se ampliado entre os pesquisadores. Entre eles, destacamos Carla S. Rodeghero (2002), que, em seus estudos, discute o conceito de imaginário anticomunista e a relação entre $o$ anticomunismo católico e a defesa dos valores cristãos frente aos processos de modernização, laicização e secularização. Temos ainda Rodrito Patto Sá Motta (2002), que avalia o impacto exercido pelo anticomunismo no Brasil nas conjunturas de 19361937 e de 1961-1964, quando as ameaças imputadas ao Comunismo forneceram o principal argumento para as duas rupturas mais significativas do período republicano para regimes autoritários. O autor aponta o universo de representações elaboradas e divulgadas pelos anticomunistas, para os quais os comunistas eram vistos como violentos, ateus, imorais, estrangeiros, traidores e até mesmo, de forma mais extrema, como o próprio diabo, com o papel de demonizar os ideais cristãos.

Entre a hierarquia eclesiástica conservadora e, em certa medida, anticomunista, o Bispo Dom Geraldo de Proença Sigaud foi um dos principais agentes nessa posição. Segundo Rodrigo Coppe Caldeira (2002), o Bispo teve um papel marcante nas polêmicas que permearam a Igreja Católica Romana nos anos 1930 até 1980. O período em questão também foi marcado pelo anticomunismo no Chile. Conforme Gabriela Gomes (2014), o 
trajeto da Juventude Conservadora Falange Nacional expressou uma ruptura radical com o projeto político de um dos partidos da direita tradicional, o Partido Conservador. O artigo analisa quais foram as percepções dos falangistas sobre o Comunismo, assim como a importância dada ao Partido Comunista como ator legítimo do sistema de partidos.

Patrick Peyton fundou, nos EUA, um movimento religioso católico denominado Holy Cross Family Ministries (HCFM) - chamado no Brasil de Cruzadas do Rosário em Família -, caracterizado pela divulgação da oração do Rosário, associada a grandes astros e estrelas do cinema e a divulgação da oração como uma arma no combate ao Comunismo, nos anos da chamada Guerra Fria. O auge do movimento do Rosário se deu entre 1948 e 1985, também auge das disputas entre EUA e URSS.

No Brasil, as Cruzadas do Rosário foram realizadas entre 1962 a 1964 em várias cidades, consolidando o imaginário anticomunista e estimulando a oração em família evidenciando, deste modo, como as atividades das Cruzadas do Rosário e a atuação do padre Peyton, podem ser consideradas como vetores que ajudaram a criar um clima propício para a aceitação do golpe civil-militar em 1964.

\section{As Cruzadas do Rosário em Família e o anticomunismo}

As Cruzadas do Rosário em Família foram realizadas no Canadá e nos EUA, em países europeus, africanos e asiáticos (Filipinas), na década de 1950. Nos países latinoamericanos, elas se intensificaram no contexto da chamada Guerra Fria e depois dos conflitos da crise dos mísseis dos EUA com Cuba, em 1962. Patrick Peyton promoveu uma grande jornada de Cruzadas no continente americano, especialmente nos países considerados áreas de influência dos EUA.

Suas nada discretas Cruzadas logo foram apontadas pelos críticos como fachada para o combate ao Comunismo e abertura aos interesses da CIA na região da América Latina. Conforme apontamos a partir de sua própria autobiografia, uma parte de sua jornada na América Latina foi financiada pela CIA, que estava interessada em combater os movimentos políticos de esquerda. A ligação com a CIA surgiu através da aproximação do padre com Peter J. Grace ${ }^{2}$, um empresário industrial dos EUA, de família irlandesa

\footnotetext{
2 In: New York Times - New York; 21/04/1995; Obituary. Disponível em: $<$ http://www.nytimes.com/1995/04/21/obituaries/j-peter-grace-ex-company-chief-dies-at81.html?pagewanted=all\&src=pm>, acessado em 15/08/2012.
} 
católica, bisneto do fundador da WR Grace and Company, uma empresa multinacional com interesses no setor de transportes, açúcar e mineração na América do Sul.

A partir de 1965, observa-se um considerável declínio nas Cruzadas do Rosário em Família. Os dois eventos com o maior número de participantes, na década de 1960, foram o de São Paulo, com um milhão e meio de participantes ${ }^{3}$, e o de Madrid, com aproximadamente um milhão de participantes, como nos informa Arnold (1983, p. 206), ambos em 1964. As Cruzadas continuaram sendo realizadas, mas com declínio considerável de participantes, com menos propaganda nos meios de comunicação e, em seguida, cancelando o agendamento de eventos em outros países. As Cruzadas realizadas nas décadas de 1970 e 1980 foram pouco numerosas, considerando-se as da década de 1960, e com muito menos impacto do que vinha ocorrendo até então.

Richard Gribble (2003) nos apresenta documentos contundentes sobre o financiamento das Cruzadas do Rosário na América Latina pela CIA. Cabe dizer que o autor é padre e membro da Congregação de Santa Cruz, a mesma de Patrick Peyton. Assim, obteve contato privilegiado com fontes exclusivas, a saber: a correspondência ativa e passiva do padre Patrick Peyton com a Santa Sé (Vaticano), com Allen Dulles (CIA) e com os superiores da Congregação de Santa Cruz.

O artigo de Richard Gribble foi publicado, em 2003, como resposta da Congregação de Santa Cruz em defesa aos questionamentos do envolvimento de Patrick Peyton com a CIA, levantados por historiadores após a abertura do processo de canonização. A ênfase do autor, embora admitindo que a origem do dinheiro fosse a CIA, foi a necessidade de demonstrar que as 'virtudes heroicas' e os frutos da evangelização do padre Peyton, através das Cruzadas do Rosário em Família, se sobrepunham à origem relativamente ilícita do dinheiro que o financiou. Para Gribble (2003), esse fato seria insuficiente enquanto argumento para que o Vaticano não desse prosseguimento ao processo de canonização de Patrick Peyton.

\section{As Cruzadas do Rosário em Família na América Latina e a Cia}

Ao observarmos os esforços do padre Patrick Peyton para direcionar as Cruzadas do Rosário em Família para a América Latina e o sucesso de público participante nos

\footnotetext{
${ }^{3}$ O ANHANGABAÚ foi o cenário da maior manifestação de fé já vista na capital. O Estado de S. Paulo, 18/08/1964 p. 14-15.
} 
países da região, buscamos evidenciar os caminhos e as articulações que possibilitaram tal êxito. No segundo semestre de 1958, ele participou da Feira Mundial, em Bruxelas, na Bélgica, onde lhe foi concedido um espaço de exposição no Pavilhão Vaticano. Em seu stand, o eclesiástico exibiu os filmes que havia gravado em 1955-1957, na Espanha. Durante o evento na Bélgica, Peter Grace o convenceu de que, na década de 1960, deveria empreender esforços na realização das Cruzadas do Rosário em Família na América Latina.

Segundo Richard Gribble (2003, p. 542), o padre Patrick Peyton conheceu o multimilionário Peter Grace em 1946, que, desde então, ajudou financeiramente as Cruzadas do Rosário em Família. Mas foi na Feira Internacional de Bruxelas, em 1958, diante do box da Cruzada do Rosário, que Grace viu pela primeira vez a exibição dos filmes dirigidos pelo padre Patrick. Conforme Arnold (1983, p.132), Grace teria dito a Peyton: "You must saturate Latin America with these films...". Ao desejar que a América Latina fosse saturada pelos filmes da Cruzada do Rosário, Peyton percebeu o potencial delas na América Latina para atender seus interesses pessoais.

A Corporação W. R. Grace \& Company tinha significativos investimentos em negócios na América do Sul, e, portanto, Peter Grace temia que o avanço do Comunismo latino-americano colocasse em risco seus empreendimentos. Segundo Gribble (2003, p. 542), ele escreveu a seu colega de trabalho: "Eu acredito pessoalmente nos efeitos de longo alcance do trabalho de Peyton como a melhor defesa possível que temos contra a ameaça comunista na América Latina...”. Patrick Peyton aceitou o investimento de Peter Grace para as Cruzadas do Rosário na América Latina, por diversas razões, entre elas, a forte influência do último junto ao governo dos EUA e ante outros empresários e políticos, que também poderiam se tornar fontes financeiras.

Pistas para compreender os caminhos de aproximação com a CIA nos são apontadas por Gribble (2003):

On 24 November,1958, one week after a meeting between Grace and Allen Dulles, director of CIA, a formalized proposal was made to the intelligence chief in a twelve-page letter. Grace outlined Peyton's earlier live and they presented details on his rosary Crusade and its efficacy in nations across the globe (...). On 3 Decembe,r 1958, Grace met with Allen Dulles and Vice President Richard Nixon at the White House to discuss the Latin American Proposal. The three men discussed Grace's proposal and Nixon approved the plan. (GRIBBLE, 2003, p.543). 
A facilidade com que Peter Grace conseguiu doações em dinheiro para as Cruzadas do Rosário levou o padre Peyton a entregar ao empresário o controle financeiro das Cruzadas. Grace estava convicto de que Patrick Peyton e as Cruzadas do Rosário em Família eram a solução para combater o Comunismo na América Latina.

Assim, nas décadas de 1960-70, as Cruzadas do Rosário em Família foram realizadas em países latino-americanos, alternando-se com Dioceses dos EUA e das Filipinas. No entanto, conforme apontado na tabela, houve uma diminuição no ritmo das Cruzadas do Rosário em Família, sobretudo, durante segunda metade da década de 1960, estendendo-se sobre a década de 1970, reduzindo-as significativamente.

Arnold (1983, p. 225), ao narrar este período da trajetória do padre Patrick Peyton, chama-o de Eclipse of Mary, ou seja, Eclipse de Maria. Para a autora, o jovem padre Peyton passou por um período de apatia e tristeza que se originaram das condições de pobreza, miséria e ignorância religiosa das pessoas nos países que visitou. Nesse período de eclipse, visitou sua terra natal, na Irlanda. Fez retiro em vários conventos, distribuiu rosários e pregou aos detentos em várias prisões.

Richard Gribble (2003, p. 558) admite a aproximação e o financiamento da CIA às Cruzadas do Rosário em Família, na América Latina, na década de 1960. Procurou justificar o ocorrido apontando o elevado custo de manutenção dos equipamentos, viagens e treinamento das equipes técnicas que acompanhavam o padre. Argumentou ainda que a pobreza econômica, a ignorância religiosa da população dos países da América Latina e o desejo de evangelizar de Patrick Peyton o levaram a ouvir os conselhos de seu amigo J. Peter Grace e aceitar o financiamento do governo dos EUA para as Cruzadas.

Desde o início das Cruzadas do Rosário em Família fora do território do EUA, o Patrick Peyton desejava realizá-las em países latino-americanos. No entanto, faltavamlhe recursos financeiros e empresários dispostos ao financiamento. Também não dispunha de contatos com os bispos das dioceses dos países que, necessariamente, precisavam autorizar a realização dos eventos da Cruzada. Apontamos brevemente os caminhos e oportunidades que o levaram a investir em uma jornada de Cruzadas do Rosário pela América Latina e, especialmente, no Brasil. Uma pista inicial nos é relatada por Peyton (1967) em sua autobiografia.

At the very same time that the Catholic Church was growing conscious of the plight of souls in Latin America, the United States was acquiring a new awareness of the problems and needs of the countries to the south and of the intimate way in which our national safety and well-being were bound up with events there. During 1958 we had watched with sympathy as a small bad of 
bearded revolutionaries expelled a unprincipled tyrant from Cuba, then recoiled during 1959 in shocked horror as they proceeded to implant a more ruthless tyranny and to form a public alliance with Soviet communism. We all welcomed in March 1961 the formulation by President Kennedy of a new common approach to hemisphere development in the Alliance for Progress. It was a total emotional climate in which the Family Rosary Crusade had everything going for it in Latin America, and we did our best to grasp the opportunity $^{4}$. (PEYTON, 1967, p.229-231).

Peyton nos apontou que seus objetivos para a América Latina estavam permeados de outras intencionalidades, especialmente o acirramento da chamada Guerra Fria, após os eventos ocorridos em Cuba, entre 1959 e 1961. Conforme VIZENTINI, (2008, p. 22), em 1959, em Cuba, o governo ditatorial de Fulgêncio Batista fora derrubado do poder por um movimento chamado 26 de julho, liderado por Fidel Castro. O grupo que tomou o governo implantou uma série de programas sociais e econômicos. Com o apoio da URSS, o movimento enfatizou seu caráter anticapitalista e antiamericano e, depois, alinhou-se ao chamado Bloco Socialista.

O momento favorável para a realização das Cruzadas do Rosário em Família na América Latina se confirmou com o programa Aliança para o Progresso, do então Presidente Kennedy, como fez questão de registrar o padre.

A Aliança para o Progresso foi um programa promovido pelo presidente americano e que foi executado entre 1961 a 1964. O objetivo era o empréstimo financeiro ou o incentivo aos investimentos privados, em países da América Latina, para combater qualquer possibilidade de aproximação dos países com o Bloco Socialista.

A Aliança para o Progresso surgiu de um relatório anterior à eleição de John F. Kennedy à presidência dos EUA, em 1960, e foi implantado logo após a sua posse como Presidente, em 1961. Segundo Silva (2008, p. 13), o relatório apresentou as fragilidades sociais nos países latino-americanos, tais como as altas taxas de analfabetismo, o déficit habitacional e outras desigualdades sociais. O contexto político dos países latinos também inquietava os EUA. Nas décadas de 1940-50, ocorreram vários levantes nesses Estados com passado colonial, advindas de concepções políticas de esquerda, em contraposição

\footnotetext{
4 "No mesmo momento em que a Igreja Católica foi tomando consciência da situação das almas na América Latina, os Estados Unidos foram adquirindo uma nova mentalidade sobre os problemas e necessidades dos países do sul e do modo particular que a nossa segurança nacional e bem-estar estavam ligados aos acontecimentos de lá. Em 1958, assistimos como um pequeno grupo de revolucionários barbudos expulsou um ditador sem princípios, de Cuba, e então recuaram, em 1959, horrorizados com a atitude deles em implantar uma tirania mais cruel ainda, e em fazer uma aliança pública com o Comunismo soviético. Todos nós acolhemos, em março de 1961, a formulação pelo presidente Kennedy de uma nova abordagem para o desenvolvimento do hemisfério na Aliança ao Progresso. Era um clima emocionante em que a Cruzada do Rosário em Familia tinha tudo a seu favor na América Latina, e nós fizemos o melhor para agarrar essa oportunidade". (Tradução Livre do autor)
} 
aos governos ditatoriais apoiados pelos EUA. Dessa forma, tivemos a Revolução Guatemalteca de 1944 e a Revolução Boliviana de 1952. Em Cuba, a derrubada do ditador Fulgêncio Batista, por luta armada de estudantes e camponeses, seguiu esta tendência.

John F. Kennedy ascendeu à Presidência dos EUA. Em seu mandato (1961-1964), buscou executar o programa Aliança para o Progresso e, propunha não apenas ajudar economicamente os países subdesenvolvidos, mas, através disso, desempenhar uma função ideológica de luta e combate ao Comunismo e às esquerdas na América Latina. Como destacou Silva (2008):

\begin{abstract}
A Aliança para o Progresso era um instrumento de luta porque visava intervir em conflitos sociais latino-americanos reais, a partir de uma série de ideias e práticas sociais que procuravam legitimar os interesses dos Estados Unidos, e, ao mesmo tempo, enfraquecer o comunismo. Esse programa tinha o objetivo de tentar convencer pessoas, grupos políticos e governos de que existia uma única via possível de transformação das condições socioeconômicas da região. Além de ser a única aceitável, a proposta norte-americana seria melhor e mais "democrática" que o projeto Comunista. (SILVA, 2008, p.19).
\end{abstract}

Através da execução do programa Aliança para o Progresso, os EUA buscavam manter o controle sobre países latinos, nos quais as agitações sociais cresciam consideravelmente. O programa incluía o fomento à propaganda ideológica, especialmente elaborando e difundindo o discurso sobre o "perigo comunista". Outra estratégia de controle dos EUA em países que supostamente representaram o "perigo comunista" foi a cooperação de treinamento policial. Conforme Rodrigo Patto Sá Motta (2010, p. 237), a United States Agency for International Development - USAID atuou no Brasil como assessoria de treinamento das corporações policiais. Para o autor, a USAID prometia aos países pobres alternativa de desenvolvimento melhor do que a via revolucionária. O programa vigorou no Brasil entre 1960 e 1972.

Conforme Arnold (1983) e Peyton (1967, p. 224), ao serem investidos bilhões de dólares no período, coordenado pelos Estados Unidos, mas advindo de diversas organizações internacionais, países europeus e empresas privadas, Patrick Peyton viu nesse programa uma chance sem igual de "agarrar essa oportunidade", como ele mesmo registrou. Precisava de muito dinheiro para o financiamento das Cruzadas do Rosário pela América Latina, pois havia aperfeiçoado a metodologia das Cruzadas com detalhes especialmente preparados para os países da região e, essa metodologia aumentava em muito os custos. 
O método para a América Latina seria o de missões populares. Os quinze filmes do Rosário, com meia hora de duração, se tornaram a principal ferramenta catequética. Padre Peyton queria fazer com que os filmes fossem vistos por tantas pessoas quanto fosse possível. Para isso, organizou unidades móveis, normalmente um veículo jipe, com equipamentos de projeção e som, acompanhados de uma equipe de divulgação. A equipe técnica exibia o filme enquanto uma catequista treinada pela equipe dava a explicação. Essa etapa era cumprida nas cinco semanas que antecediam a realização da grande concentração final da Cruzada do Rosário em Família.

Em suas memórias, Patrick Peyton apresenta suas representações sobre o Catolicismo, no Chile, o primeiro dos países sul-americanos a realizar as Cruzadas do Rosário, em 1960. Ele registrou que a América Latina é duas vezes e meia o tamanho dos Estados Unidos e com uma população imensa, com a maior taxa de natalidade do mundo. Metade da população estaria nas áreas rurais, em lugares tão distantes que raramente teriam contato com um padre.

Ao relatar a visita a Dom Manuel Larraín ${ }^{5}$, para pedir a bênção para as Cruzadas do Rosário em Família no Chile, Patrick Peyton registrou a posição político-ideológica do prelado, em desacordo com os projetos do anticomunismo católico norte-americano: "Seu chamado para a reforma agrária foi constante". "O Comunismo passeia sobre os ombros de um campesinato descontente". Disse Peyton (1967, p.223): "Se todo homem é dono de uma propriedade, ela vai perder seu sentido".

O Bispo Dom Manuel Larraín, em 1960, era o vice-presidente do Conselho Episcopal Latino-Americano (CELAM), e, em 1965, tornou-se presidente daquele conselho. Em momento algum do relato de Patrick Peyton, narra-se o embate de ideias ou de posições com o prelado, no entanto, ele pareceu conseguir o apoio e as bênçãos do bispo às Cruzadas do Rosário em Família no Chile.

Muito antes de encerrar a jornada das Cruzadas do Rosário em Família em dez dioceses no Chile, o padre Peyton já havia se articulado enviando cartas a vários bispos de outros países da América Latina. Ele se lembrou do apelo do Papa Pio XII para que as ordens religiosas católicas da América do Norte enviassem dez por cento de seus

\footnotetext{
${ }^{5}$ Manuel Larraín Errázuriz (1900-1966). Bispo de Talca no Chile. Participou ativamente do primeiro no Congreso Eucarístico de 1955, no Rio de Janeiro ,e logo no Concílio Vaticano II (1962-1965). O fruto do primeiro evento foi o nascimento da "Conferência Episcopal para América Latina" (CELAM), na qual Dom Manuel Larraín foi eleito vice-presidente. Em 1964, assumiu como presidente da CELAM, instância na qual foi reconhecido como um grande líder da Igreja latino-americana. Participou ativamente no processo de organização do Concílio Vaticano II. Disponível em: http://www.centromanuellarrain.cl/htm/bio_portugues.htm. Acessado em jun. 2012.
} 
missionários para trabalhar na América Latina ao prazo de dez anos. Foi nesse contexto que Christopher O'Toole, superior geral da Congregação dos Padres da Santa Cruz, escreveu uma carta-circular, enviada a todos os membros da Congregação das províncias dos EUA, solicitando que fizessem o possível para enviar missionários para a América Latina, para ajudar o padre Patrick Peyton na realização das Cruzadas do Rosário em Família.

O novo superior-geral da Congregação dos Padres da Santa Cruz, padre GermainMarie Lalande, em 1962, reafirmou a importância do projeto para a América Latina, em uma carta-circular aos missionários de sua ordem. No documento, apontou que esperava que as Cruzadas do Rosário na América Latina produzissem frutos “... it can be regarded as one of the most effective means of preventing the peoples of Latin America from sinking rapidly into materialism and becoming the prey of communism." (Peyton, 1967, p.226). Lalande registrou, ainda, que George DePrizio, superior imediato ${ }^{6}$ do padre Patrick Peyton, tratava as Cruzadas do Rosário em Família como uma parte importante da resposta de sua província ao apelo do Papa Pio XII.

A jornada das Cruzadas do Rosário em Família na América Latina foi iniciada no Chile, em 1960. As expectativas de grande sucesso das Cruzadas foram surpreendidas por manifestações contrárias a elas naquele país, como nos aponta Arnold (1983):

\begin{abstract}
There were sometimes hecklers in the crowds. Anti-crusade protests were spread by some who feared religious as a foe of their special interests, especially in the labor unions where men were made vulnerable by material needs and in the universities where young idealists hoped to heal the ills of their world. Communists were especially vocal, although few in number, in courting the young students who were the future leaders of their country. Father Peyton wanted to court them for God and insisted on taking the crusade to the campuses, in spite of sometimes angry and loud demonstrations ${ }^{7}$. (ARNOLD, 1983, p. 156).
\end{abstract}

Patrick Peyton registrou que houveram protestos de jovens estudantes contrários à realização das Cruzadas do Rosário no Chile. Para ele, os protestos foram um sinal de confirmação da necessidade de as Cruzadas do Rosário em Família combaterem o

\footnotetext{
${ }^{6}$ As congregações religiosas dividem-se em regiões eclesiásticas chamadas de províncias, sob o comando de um superior. Em Roma, há um superior-geral da congregação.

${ }^{7}$ Houve algumas vezes baderneiros entre as multidões. Protestos contra a Cruzada foram espalhados por alguns que temiam a religião como sendo um inimigo de seus interesses, especialmente nos sindicatos, onde os homens foram feitos vulneráveis por necessidades materiais, e nas universidades, onde jovens idealistas esperavam curar os males do seu mundo. Comunistas eram especialmente comunicativos, embora em número reduzido, em conquistar os jovens alunos, que eram os futuros líderes de seu país. Padre Peyton queria conquistá-los para Deus e insistiu em levar a Cruzada para os campi, apesar de manifestações às vezes altas e enfurecidas. (Tradução livre do autor)
} 
suposto perigo iminente do Comunismo na América Latina. Arnold (1983, p. 165), ao avaliar os resultados da Cruzada do Rosário em Família, no Chile, citou a resposta do Bispo Larraín ao padre Peyton, abordando a dimensão das intervenções políticas resultantes das Cruzadas:

He said to Father Peyton, "Communism rides on the shoulders of a discontented peasantry. If every man is a property owner, it will lose its appeal." President Alessandri visited the Santiago headquarters toward the end of the Crusade in Chile. The losses from the great earthquakes were still being counted. The disaster so devastated Chile's economy that in later years the democratic faction was unable to bind the country and it fell to the Communist Salvador Allende. But the Crusade had brought such a revival of faith that President Alessandri wanted to thank Father Peyton personally ${ }^{8}$. (ARNOLD, 1983, p.165).

Embora Peyton tenha escrito em sua autobiografia que a jornada das Cruzadas do Rosário em Família na América Latina almejasse um financiamento da Aliança para a América, ${ }^{9}$ promovida pelo Presidente Kennedy, ele não nos dá pistas sobre as articulações para conseguir o dinheiro. No entanto, Richard Gribble (2003, p. 545) revela e procura justificar as razões que levaram Peyton a aproximar-se da Casa Branca e, indiretamente, aceitar dinheiro da CIA para realizar as Cruzadas do Rosário em diversos países na América Latina, entre eles o Brasil. Admitiu essa aproximação e apontou os nomes dos principais patrocinadores. Também apontou uma série de documentos que comprovam tais fatos, inclusive uma advertência que Patrick Peyton recebeu do próprio Papa Paulo VI.

Ao conseguir o financiamento para a jornada das Cruzadas na América Latina, Peyton encontrou, nos países latino-americanos, especialmente no Brasil, uma estrutura política de poder receptiva ao capital multinacional e, portanto, um contexto propício aos seus desdobramentos. Nesse sentido, nos é pertinente o que aponta René Armand Dreifuss (2008):

Os interesses multinacionais e associados cresceram rápida e estavelmente, estimulados pela política de desenvolvimento de Juscelino Kubitschek. Por volta de 1960, tais interesses haviam se tornado a força socioeconômica dominante. Ao mesmo tempo em que o processo ocorria, um novo conjunto de

\footnotetext{
${ }^{8}$ Ele disse ao padre Peyton, "o comunismo passeia sobre os ombros de um campesinato descontente. Se todo homem for um proprietario, ele perderá seu encanto." O Presidente Alessandri visitou a sede em Santiago no final da Cruzada no Chile. As perdas dos grandes terremotos ainda estavam sendo contadas. O desastre devastou a economia do Chile, que nos últimos anos a facção democrática não foi capaz de reerguer o país e caiu para o comunista Salvador Allende. Mas a Cruzada havia trazido tal reavivamento da fé, que o presidente Alessandri queria agradecer pessoalmente ao padre Peyton. (Tradução livre do autor)

${ }^{9}$ Peyton se referiu ao Programa Aliança para o Progresso, promovida pelo Presidente Kennedy.
} 
agentes sociopolíticos aparecia na economia e na política brasileiras. Esses agentes formaram um aparelho civil e militar modernizante responsável pelos assuntos relativos à produção e à administração política do bloco econômico multinacional e associado. (DREIFUSS, 2008, p.78).

Dreifuss descreve o que chamou de "estrutura de poder político de classe do bloco multinacional e associado". Para o autor, essa estrutura tomava forma nos chamados "intelectuais orgânicos", que eram: os diretores de corporações multinacionais, administradores de empresas privadas ou técnico-executivos estatais, oficiais militares. Assim, os interesses externos, especialmente o programa Aliança para o Progresso, receberam apoio político dos governos e dos empresários onde foram implantados, minimizando as formas de resistência à sua implementação.

Conforme Richard Gribble (2003, p. 548), Peter J. Grace tinha ligações com Allen Dulles, secretário de Richard Nixon, que, ao conhecer o projeto de Patrick Peyton para a América Latina, manifestou entusiasmo. A CIA decidiu liberar fundos para a Cruzada na América Latina, especialmente no Chile, Brasil, Venezuela e Colômbia. O superior provincial de Patrick Peyton, Padre Richard Sullivan, ao tomar conhecimento do financiamento pela CIA, levou o caso ao Vaticano, que tentou persuadir Patrick Peyton a desistir da ajuda financeira da CIA, pois temia que, se a origem do dinheiro se tornasse pública, poderia haver um escândalo que abalaria tanto a Congregação de Santa Cruz, como a Igreja Católica.

\section{A Cruzada do Rosário em Família em São Paulo, em 1964}

As Cruzadas do Rosário em Família foram realizadas no Brasil, com programação semelhante às das demais em outros países da América Latina. Foram realizadas em sete capitais dos Estados: Rio de Janeiro (1962), Recife (1962), Salvador (1963), Belo Horizonte (1963), Porto Alegre (1963), Curitiba (1964), São Paulo (1964) Dentre estas, escolhemos tratar do evento em São Paulo, em 1964, por ter sido preparado e divulgado nos meses que antecederam ao golpe civil-militar. O grande evento público da Cruzada ocorreu no dia 08 de agosto, depois da ascensão militar ao governo do país.

A decisão de incluir o Brasil no roteiro do padre Patrick Peyton, entre 1962 e 1964, aconteceu em Roma. Para as sessões do Concílio Vaticano II, estavam convidados apenas bispos e cardeais. No entanto, Peyton percebeu que circular no Vaticano durante uma 
concentração de membros do alto clero seria uma oportunidade singular de fazer bons contatos para a ampliação das Cruzadas do Rosário. Conforme (Peyton, 1967)

The Council sessions were also extraordinarily rich for the Family Rosary Crusade and for me personally in countless other ways. They provide a unique opportunity to meet not only individual bishops and small groups at a time, but to meet entire national hierarchies and to discuss with them the spiritual and pastoral benefits they expected from the Crusade, this at the very moment when they were discussing among themselves their long-term plans for their dioceses and regions ${ }^{10}$. (PEYTON, 1967,p. 249)

Foi no início do Concílio Vaticano II que Peyton (1967, p.249) obteve a aceitação do Cardeal Dom Jaime de Barros Câmara, do Rio de Janeiro, para a realização da primeira das sete Cruzadas do Rosário agendadas para o Brasil entre 1962 e 1964. "My talks with leading Brazilian bishops were particularly valuable."11.

Na perspectiva metodológica, Tania Regina de Luca é adotada na construção desse texto: conforme ela, a história por meio de periódicos nos permite uma infinidade de abordagens. Entre os diversos aspectos apontados, estaremos mais atentos às questões que envolvem o conteúdo e os seus idealizadores.

\footnotetext{
${ }^{10}$ As sessões do Conselho também foram extraordinariamente ricas para a Cruzada do Rosário para a Família e para mim, pessoalmente, em inúmeras maneiras. Elas proporcionam uma oportunidade única não só de encontrar pessoalmente com os bispos e pequenos grupos, mas para atender as hierarquias nacionais e discutir com eles os benefícios espirituais e pastorais que eles esperavam da Cruzada, isso no exato momento em que eles estavam discutindo entre eles os seus próprios planos de longo prazo para suas dioceses e regiões. (Tradução Livre do Autor)

${ }^{11}$ Minhas conversas com os bispos brasileiros foram particularmente valiosas.
} 


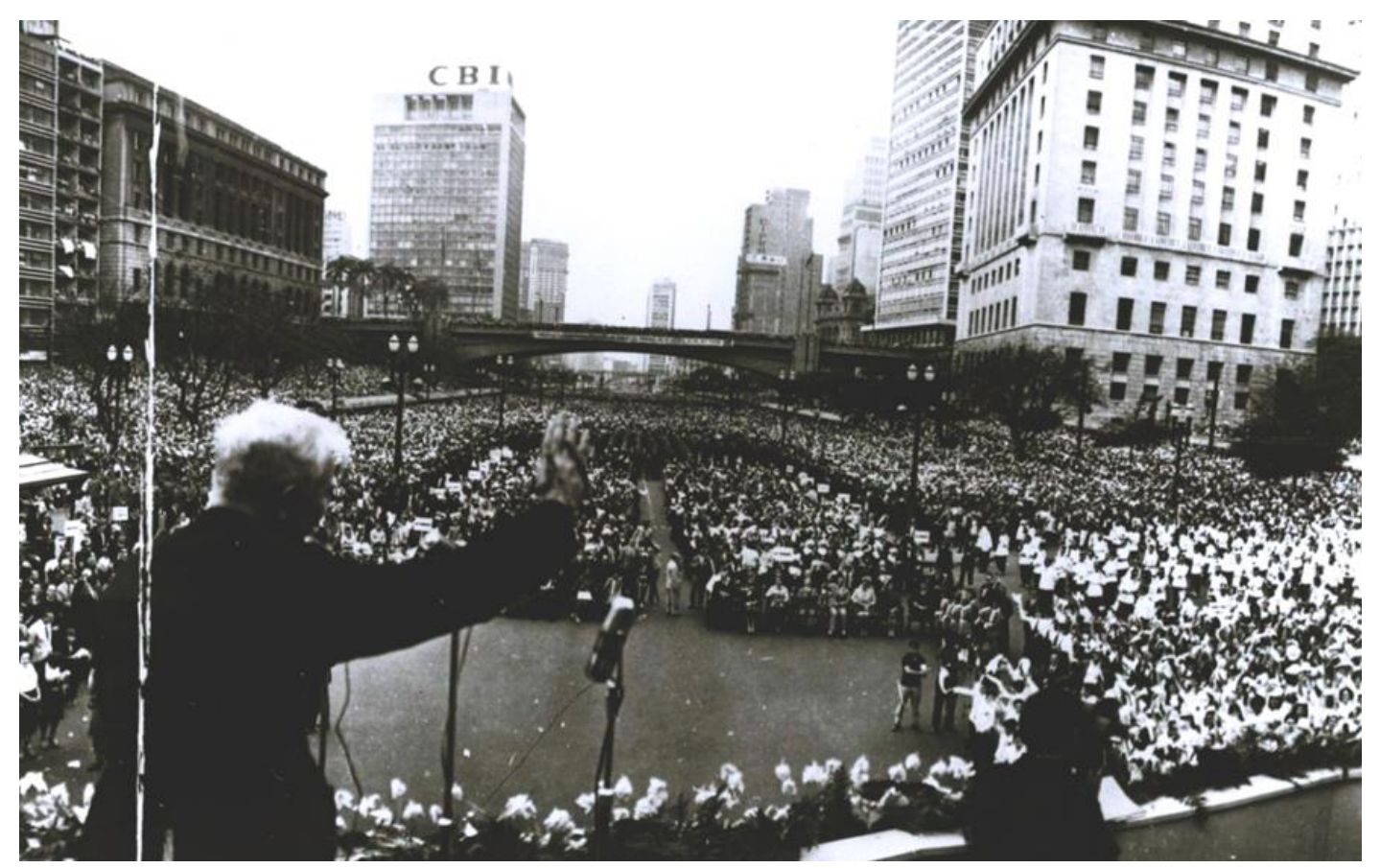

Figure 1: Padre Patrick Peyton no Vale do Anhangabaú - SP, pregando a 1,5 milhão de pessoas em 8 de agosto de 1964. Fonte: O Estado de S. Paulo, 08/08/1964, p.01

Em 1964, a Cruzada do Rosário em Família realizou suas atividades na cidade de São Paulo. Os preparativos foram iniciados no mês de fevereiro. A grande concentração pública aconteceu no Vale do Anhangabaú, no mês de agosto, portanto, após a deposição do Presidente da República, João Goulart, e a ascensão dos militares ao poder. Embora em sua pregação no Vale do Anhangabaú, o padre Patrick Peyton não tenha feito nenhuma referência aos acontecimentos políticos, analisamos aspectos de seu discurso. Em 1983, Jeanne Gosselin Arnold (1983), uma integrante da equipe central das Cruzadas do Rosário, publicou uma biografia do padre Peyton e, em sua narrativa, dedicou um capítulo aos acontecimentos políticos no Brasil durante a realização das Cruzadas do Rosário em Família. A autora, por sua vez, reservou um capítulo de sua obra para, do seu ponto de vista, explicar os acontecimentos políticos de 1964 no Brasil durante a realização da etapa de preparação da Cruzada do Rosário em Família na cidade de São Paulo.

\section{A "REDENÇÃO DO BRASIL": O discurso anticomunista da Cruzada do Rosário em Família}

Com o curioso título de Caldeirões ferventes do Brasil, Arnold registrou seu entendimento sobre os embates e o desfecho político no Brasil durante a realização da 
Cruzada do Rosário em Família. Ela iniciou seu texto afirmando que o chefe do governo estava planejando secretamente acabar com a democracia constitucional. Explicou que João Goulart não havia sido eleito Presidente da República, mas, por ser vice-presidente, assumiu o cargo após a renúncia de Jânio Quadros. Registrou a importância e influência política de uma classe média advinda da recente industrialização. Segundo a autora, essa classe média, favorável à democracia, aliou-se a outros grupos influentes, entre eles os oficiais do Exército, a fim de garantir a continuidade democrática nas formas de governo. Para eles, essa garantia se tornava possível com a eliminação da difusão dos ideais e das estratégias terroristas e violentas, preparadas por grupos comunistas treinados em Havana.

A autora (1983, p. 193) se lembrou da organização das mulheres, esposas de classe média, que, em 1962, invadiram a redação do jornal $O$ Globo para protestar contra a nomeação de Hermes Lima, Primeiro-Ministro, apontado por elas como comunista. Ainda a respeito da organização feminina, descreveu ações da Campanha da Mulher pela Democracia (CAMDE) como sendo divulgação e propaganda anticomunista através do envio de cartas pelo correio, entregadas pessoalmente de casa em casa e, até mesmo, enviadas através de taxis pagos por elas por ocasião de uma greve dos Correios.

Patrick Peyton parecia conhecer os contrastes sociais brasileiros, pois, conforme Arnold, o padre visitou os lixões do Rio de Janeiro, em 1962, e conversou com os moradores desses lugares; a conclusão dessa visita, registrada pela autora, nos impressiona. Peyton disse à população que eles eram tão amados e queridos por Deus e pela Virgem Maria como qualquer pessoa, e que tinham a mesma oportunidade para alcançar a vida eterna. Segundo Arnold, alguns dos visitados acolheram as palavras, já outros responderam que a morte seria a única saída para eles.

Reconhecemos no texto de Arnold indícios de que a Cruzada do Rosário em Família compartilhava com outros grupos anticomunistas a ideia de que um confronto entre as classes levaria a uma revolução comunista:

To the poor, to the middle classes who were only a step above them with low incomes consumed by skyrocketing inflation, and to the aristocracy, Father Peyton brought the same message, in the same words and in the same loving manner. Their political affiliations did not concern him. There were no inequities among souls. He could not alter their material lives, but he could tell them how to appeal to their Blessed Mother for help ${ }^{12}$. (ARNOLD, 1963, p.163).

12 Ibidem, p.193. Para os pobres, para as classes médias que estavam apenas um passo acima deles com baixos rendimentos consumidos pela disparada da inflação, e para aristocracia, o padre Peyton trouxe a 
A narrativa sobre os conflitos políticos no Brasil foi interrompida repentinamente no texto de Arnold. Nas páginas 194 e 195, ela registrou que entre os preparativos das três Cruzadas do Rosário em Família programadas para o ano de 1963 no Brasil (Salvador - BA, Belo Horizonte - MG e Porto Alegre - RS), Patrick Peyton viajou à cidade de Madrid (Espanha) para uma reunião com o Primeiro-Ministro, Carrero Blanco, e Antonio de Oriol y Urquijo, amigo pessoal do padre. Tratou-se da confirmação e da formalização do convite feito pelo governo espanhol ao religioso, para que realizasse a Cruzada do Rosário em Família no mês de maio de 1964, na cidade de Madrid, como um evento de Ação de Graças pelos vinte e cinco anos da vitória do General Francisco Franco na Guerra Civil Espanhola ${ }^{13}$.

O Primeiro-Ministro espanhol perguntou a Peyton: "Quanto dinheiro você acha que você vai precisar para realizar a Cruzada aqui?". O padre respondeu que dez mil dólares seriam suficientes, mas segundo Arnold, as doações foram muito maiores, embora ela não apontasse o montante conseguido. A Cruzada do Rosário em Madrid foi realizada em maio de 1964 e, na avaliação de Arnold, ela está entre as que obtiveram maior número de pessoas participantes na década de $1960^{14}$.

Após explicar o que foram os Caldeirões ferventes no Brasil, Arnold (1983, p.198) escreveu um subcapítulo com o título Redenção do Brasil. O texto descreve os preparativos e a realização da Cruzada do Rosário em Família na cidade de São Paulo, da qual já tratamos. Nos parágrafos iniciais, enfatizou o paradoxo de uma cidade populosa, com poucos padres e paróquias para atender as pessoas. Destacou que os pobres eram os maiores vitimados, especialmente, por permanecerem na ignorância religiosa e, portanto, ficavam mais vulneráveis a doutrinas que chamou de "perigosas", ao fazer menção ao Comunismo. Para Arnold (1983),

\footnotetext{
Since the basic problem of poor families was a moral one, father Peyton told them, the basic solutions was a religious one.

By strengthening the moral fiber of families, he said, we can strengthen their society to bring about their own improvement in self-help - cooperative learning and services. The poor, however, lacked the values for motivation to improve their own lives. Whatever leadership they had was either untrained
}

\footnotetext{
mesma mensagem, com as mesmas palavras e da mesma maneira amorosa. Suas filiações políticas não lhe dizem respeito. Não houve desigualdades entre almas. Ele não poderia alterar suas vidas materiais, mas ele poderia dizer-lhes como apelar à sua Mãe Santíssima para obter ajuda. (Tradução livre do autor)

13 ARNOLD, 1983, p.194.

${ }^{14}$ Idem, p. 194.
} 
and without resources or trained in fomenting chaos $^{15}$. (ARNOLD, 1983, p.198).

Assim como nas pregações públicas na grande concentração das Cruzadas do Rosário em Família, Peyton não abordava diretamente o Comunismo como inimigo. A estratégia consistia em convencer sobre a importância da unidade familiar e dos valores cristãos inerentes a ela. Em oposição à família, estaria o Comunismo, fomentado por seus líderes e que levaria ao caos.

Depois de descrever a realização da Cruzada do Rosário em Família, em São Paulo, Arnold explicou o porquê da escolha do título do texto como Redenção do Brasil. Para isso, articulou no texto a descrição das principais manobras políticas que aconteceram no mês de março de 1964 e que levaram ao golpe civil-militar.

No mês de março de 1964, estava acontecendo a grande campanha publicitária em preparação à Cruzada do Rosário em Família, com anúncios nos jornais, nas revistas, em outdoors, nos programas de rádio e de televisão. Segundo Arnold (1983, p.200), os bispos exortaram a população a “... implorar a ajuda de Maria, especialmente, de Nossa Senhora de Fátima, que prometeu um fim para a guerra através da oração ao seu Imaculado Coração". Os manuais da Cruzada do Rosário em Família já haviam sido distribuídos nas paróquias, nas escolas e em outros inumeráveis lugares. Muitas mulheres militantes da CAMDE eram, ao mesmo tempo, fervorosas católicas e estavam também alistadas entre os voluntários para a organização da grande concentração pública da Cruzada.

Arnold compartilha da hipótese de que havia um plano secreto de uma Revolução Comunista em curso:

Communists stirred the cauldrons of the nation's troubles brewing revolution. President João Goulart was an ambitious man. He schemed to use the radical left to destroy the legal democracy and replace it with dictatorship under his rule, trough which he expected to grab personal wealth and total power. He made deals with Russia and fulfilled his part of the bargain by appointing undercover Communist agents to key government positions. (ARNOLD, 1983, p. 192).

\footnotetext{
${ }^{15}$ Ibidem, p.198. Se o problema básico das famílias pobres era uma questão moral, o Padre Peyton disse a eles que a solução seria a religião. Ao fortalecer a fibra moral da família, disse ele, se pode fortalecer e ajudar a sociedade a ser melhor - com a aprendizagem cooperativa e serviços. Os pobres, no entanto, não tinham motivação para melhorar suas próprias vidas. Qualquer que seja a liderança que eles tinham era tanto destreinada e sem recursos ou treinados para fomentar o caos. (Tradução livre do autor)
} 
Ao compartilhar do ponto de vista dos estadunidenses, para os quais havia um plano soviético para desencadear uma Revolução Comunista no Brasil e, que o presidente João Goulart seria o principal instrumento desse plano, Arnold afirmou que, assim como em outros países latino-americanos, no Brasil, grandes latifundiários controlavam o poder e os pobres trabalhavam para eles. "But latifundia were modified in Brazil by the existence of a growing middle class of business and professional men born of growing industrialization". 16

O principal responsável pelo golpe civil-militar, segundo Arnold, foi o presidente João Goulart:

Suddenly, unexpectedly, Brazil's President Goulart ridiculed the Rosary! On nationwide television and radio on Mar 13, he said, "Why do toy pray the Rosary? The Rosary can't save you now." Goulart was now profaning the Rosary before all Brazil. Brazilians listened in horror as he continued with the words that tolled the demise of their democratic form of government. Goulart issued two decrees of confiscation, actually signing them before the cameras. The decrees gave the six remaining privately owned oil refineries to the government monopoly and confiscated large tracts of land judged inadequately operated, allegedly for distribution to landless peasants. The president called the government and social order 'outmoded' and demanded basic changes in the constitution. His chief spokesman Brizola followed, demanding abolition of Congress and substitution of a governing body of peasants, workers and low-level military troops. It was government by decree. ${ }^{17}$ (ARNOLD, 1983, p.200).

Para a autora, o fato de o presidente João Goulart ter mencionado o movimento do Rosário em público foi entendido como uma afronta por milhares de pessoas, que já conheciam as Cruzadas do Rosário em Família no Brasil. Em 1964, as grandes concentrações públicas organizadas pela equipe de Patrick Peyton já tinham sido realizadas no Rio de Janeiro, em Salvador, em Recife, em Porto Alegre e em Belo Horizonte. Nas cidades de Curitiba e São Paulo, as Cruzadas do Rosário estavam em fase de divulgação e, portanto, criando expectativas entre as pessoas.

\footnotetext{
${ }^{16}$ Idem, p.192. Mas os latifúndios foram modificando no Brasil pela existência de uma classe média empresarial e profissional que nasceu da crescente industrialização. (Tradução livre do autor)

${ }^{17}$ De repente, de forma inesperada, o presidente do Brasil João Goulart ridicularizou o Rosário! Na televisão e rádio em todo o país em 13 de março, ele disse: "Por que brincar de rezar o Rosário? O Rosário não pode salvá-lo agora." Goulart estava profanando o Rosário diante de todo o Brasil. Os brasileiros ouviram horrorizados enquanto ele continuava com as palavras que soaram o fim da sua forma democrática de governo. Goulart emitiu dois decretos de confisco, na verdade, assinou-os diante das câmeras. Os decretos passaram as seis restantes refinarias de petróleo de propriedade privada para o monopólio do governo e confiscou grandes extensões de terra inadequadamente julgado operado, alegadamente para distribuição aos camponeses sem terra. O presidente chamou a ordem governamental e social "fora de moda" e exigiu mudanças fundamentais na Constituição. Seu principal porta-voz Brizola seguiu, exigindo a abolição do Congresso e substituição de um órgão de camponeses, trabalhadores e baixo nível de tropas militares por um decreto do governo. (Tradução livre do autor).
} 
Não encontramos nenhuma manifestação direta do padre sobre esses acontecimentos, sequer em sua autobiografia. No entanto, mais uma vez, nos aportamos nos registros de Arnold:

To Father Peyton, denying the power of the Rosary was the same as denying Mary's role as the Mother of God. It was the same as denying her relationship with her Son Jesus and her role as mother of all mankind. It was the same as repudiating Christianity itself. Father Peyton's explanation of the Rosary as the embodiment of the tenets of Christianity had been spread throughout Brazil $^{18}$. (ARNOLD, 1983, p.201).

Esta afirmativa de Peyton, segundo a autora, levou os cristãos a entender que Goulart refutou não somente o objeto Rosário, mas a própria mãe de Deus e, analogamente, as mães de família.

Conforme Arnold, o comício do dia 13 de março de 1964, na Estação Central do Brasil, no qual o Presidente João Goulart anunciou as chamadas Reformas de Base, desencadeou as ações dos líderes do golpe civil-militar. Entre os argumentos do presidente João Goulart, os mais incisivos foram os confiscos de terras e a nacionalização das refinarias de petróleo, que, segundo a autora, contrariavam o direito à propriedade, que constava na constituição vigente. Por fim, ela acusa Leonel Brizola, cunhado do presidente João Goulart, então Deputado Federal, de ser o porta-voz do suposto Plano Comunista, ao exigir o fechamento do Congresso Nacional e a substituição dos parlamentares por trabalhadores e militares de baixa graduação hierárquica.

Arnold (1983) reforça a ideia de que os comunistas tinham um plano sequenciado para tomar o poder:

It was modeled on Lenin and was a replay of Castro's scenario as he turned Cuba over to the Communists. Brazil's middle class realized the crisis has arrived. There would be no turning back by this government. Goulart's actions were bound to bring on civil war, followed by Communist takeover. ${ }^{19}$ (ARNOLD, 1983, p.200).

O suposto plano determinava que o início da Revolução Comunista na América Latina fosse iniciado no Brasil, considerado um país estratégico para o continente, pois os demais

\footnotetext{
${ }^{18}$ Para o Padre Peyton, negar o poder do Rosário era o mesmo que negar o papel de Maria como Mãe de Deus. Era o mesmo que negar a relação dela com seu Filho Jesus e seu papel de mãe de toda a humanidade. Era o mesmo que repudiar o cristianismo. A explicação do Padre Peyton sobre o rosário como a incorporação dos dogmas do cristianismo espalhou-se Brasil a fora. (Tradução livre do autor)

${ }^{19}$ Foi inspirado em Lênin e copiado do cenário de Castro enquanto tornava Cuba comunista. A classe média do Brasil percebeu que a crise havia chegado. Não haveria como voltar atrás neste governo. As ações de Goulart trariam obrigatoriamente a guerra civil, seguido pelo domínio comunista. (Tradução livre do autor)
} 
países fariam o mesmo em seguida. Arnold continuou sua narrativa dos acontecimentos do mês de março de 1964 com sua versão sobre a organização da Marcha da Família com Deus pela Liberdade, realizada na cidade de São Paulo no dia 19:

On March, 19, the women of São Paulo swarmed out of their houses. They jammed the broad downtown boulevards of São Paulo, over a million women strong, carrying Rosary beads. Newspapers, headlining the women's 'Proclamation,' were being sold on the streets as they marched. The proclamation said the country was 'in extreme danger' and had allowed 'men of limitless ambition without Christian faith or scruples ... to create hate and despair." The infiltration by 'servants of totalitarianism, foreign to us and allconsuming.' The proclamation concluded with "Mother of God, preserve us form the fate and suffering of the martyred women of Cuba, Poland, Hungary and other enslaved nations". The women called their demonstration "The march of the Family with God toward Freedom. Similar demonstrations followed in other major cities despite police efforts to halt the crusading women. ${ }^{20}$ (ARNOLD, 1983, p.202).

Para Arnold, as mulheres e as atividades de propaganda anticomunista foram de fundamental importância para construir uma opinião pública que levasse as pessoas a se sentirem inseguras, em perigo diante das ações do presidente João Goulart. A sequência da narrativa, mesmo com textos publicados em circunstâncias e épocas totalmente diversas, convergiu para uma interpretação comum sobre as ações dos militares, sintetizada por Arnold:

Working in secret, the army generals, aided by navy officers and middle-class businessmen, organized a military takeover of the government. Their columns marched on March 31 and by mid-day of April 1 it was all over. Goulart fled to Uruguay and his conspirators fled or hid where they could.

Humberto Castello Branco, the army chief of staff who had been most instrumental in engineering the bloodless counter-revolution, was named by the Chamber of Deputies to serve Goulart's unexpired term as president. ${ }^{21}$ (ARNOLD, 1983, p.202)

\footnotetext{
${ }^{20}$ Em 19 de março, as mulheres de São Paulo saíram de suas casas. Elas invadiram as avenidas largas do centro de São Paulo, mais de um milhão de mulheres fortes, levando o Rosário. Panfletos com a "proclamação" das mulheres estavam sendo vendidos nas ruas enquanto marchavam. A 'proclamação' disse que o país estava "em perigo extremo" e permitiu "homens de ambição sem limites, sem fé cristã ou escrúpulos... gerarem ódio e desespero". A infiltração por 'servos do totalitarismo, estranhos para nós e que tudo consomem'. O panfleto concluiu com "Mãe de Deus, preserva-nos do mesmo destino e sofrimento das mulheres martirizadas de Cuba, Polônia, Hungria e outros países escravizados". As mulheres chamaram sua demonstração "A marcha da Família com Deus para a Liberdade." Manifestações similares aconteceram em outras grandes cidades apesar dos esforços da polícia para deter as cruzadas das mulheres. (Tradução livre do autor)

${ }^{21}$ Trabalhando em segredo, os generais do exército, auxiliados por oficiais da Marinha e da classe média empresarial, organizaram um golpe de Estado militar para o governo. Suas colunas marcharam em 31 de março e, por volta do meio-dia de $1^{\circ}$ de abril, estava tudo acabado. Goulart fugiu para o Uruguai e seus conspiradores fugiram ou esconderam-se onde puderam. Humberto Castello Branco, o chefe do Exército que havia sido praticamente instrumental em engenhar a contrarrevolução sem derramamento de sangue, foi nomeado pela Câmara dos Deputados para servir o prazo vigente de Goulart como presidente. (Tradução livre do autor)
} 
Por fim, Arnold apresentou sua percepção sobre a participação da Cruzada do Rosário em Família no golpe civil-militar. Segundo a autora, Patrick Peyton foi coautor das 'Forças Misteriosas' trazidas para o Brasil juntamente com as Cruzadas do Rosário e com uma torrente de orações. Para a autora, o Rosário trouxe um milagre de coesão de todas as forças que se uniram para o que foi chamado de "milagre da unidade nacional".

The people and the soldiers, in harmony with the same faith in God, and confidence in Brazil, were able to reach their ideal, without bloodshed, in the glow of the beads of the Rosary." Everywhere Brazilian were giving thanks to the Virgin of Fatima for the miracle of revolution without bloodshed ${ }^{22}$. (ARNOLD, 1983, p. 202).

Ao afirmar que a 'Redenção do Brasil' ocorreu por consequência da união entre soldados e as pessoas civis que, harmonizados pela mesma fé e confiança, através do Rosário, evitaram o derramamento de sangue, compartilha a opinião dos historiadores que explicam a ascensão dos militares no Brasil.

Depois da realização das Cruzadas no Brasil, especialmente em 1964 e 1965, houve uma diminuição das atividades do padre Patrick Peyton e dos eventos organizados pela equipe que o acompanhava. Esse declínio foi nominado pelo padre de "Eclipse de Maria". Conhecemos por eclipse o fenômeno em que a Lua se põe entre o Sol e a Terra e, ao projetar a sombra lunar sobre a Terra, causa a impressão de que o Sol estaria desaparecendo. A analogia usada pelo clérigo foi tomada nessa pesquisa como um indício de havia uma explicação oculta para o 'frear' das Cruzadas do Rosário em Família.

Ao buscar explicações para o declínio das Cruzadas do Rosário em Família a partir de 1965, recorremos novamente a Richard Gribble (2003). O autor, por ser membro da Congregação de Santa Cruz, a mesma ordem religiosa de Peyton, obteve acesso à fontes privilegiadas, como cartas trocadas entre o padre e o Superior-Geral da Congregação de Santa Cruz, Germain Lalande. Também estão entre as fontes, cartas entre o Patrick Peyton e o tesoureiro-geral das Cruzadas, Peter Grace, e outras fontes do arquivo da Congregação. Em sua narrativa, Richard Gribble abordou repreensões que Congregação de Santa Cruz e, até mesmo, do Vaticano, impuseram a Peyton, ao tomarem conhecimento de que as Cruzadas do Rosário em Família na América Latina estavam sendo patrocinadas pela CIA.

\footnotetext{
22 O povo e os soldados, em harmonia com a mesma fé em Deus e confiança no Brasil, foram capazes de alcançar seus ideais, sem derramamento de sangue, no brilho das contas do Rosário. Em todos os lugares brasileiros estavam dando graças à Virgem de Fátima pelo milagre da revolução sem derramamento de sangue. (Tradução livre do autor)
} 


\section{Considerações finais}

Debruçamo-nos sobre as ações do padre Patrick Peyton e sobre as Cruzadas do Rosário em Família no Brasil. Entre as sete capitais brasileiras que realizaram os eventos promovidos pelas equipes de Peyton, optamos por estudar as Cruzadas realizadas na cidade de São Paulo, em 1962. Ela iniciou-se no governo de João Goulart, antes do golpe civil-militar e terminou no mês de agosto de 1964, já no período de consolidação dos militares no poder.

As Cruzadas do Rosário em Família na América Latina receberam ajuda financeira da CIA. O acordo entre o governo dos EUA e as Cruzadas do Rosário em Família durou seis anos (1959 a 1965), conforme relatado. É importante lembrar de que as Cruzadas do Rosário em Família foram iniciadas pelo padre Patrick Peyton em sua diocese como agradecimento à Virgem Maria pela cura de sua tuberculose. Depois, a partir da insistência de Peyton através das cartas enviadas aos bispos, se tornaram sucesso entre os católicos dos EUA e Canadá, sendo financiadas pelas dioceses que recebiam Patrick Peyton e suas equipes. Vários países europeus receberam as Cruzadas do Rosário, compartilhando os custos entre as dioceses e congregações religiosas mais ricas, especialmente, aquelas que eram proprietárias de universidades, colégios ou grandes hospitais. Muitas dessas dioceses financiaram a ida do clérigo a países africanos e asiáticos. Os espanhóis financiaram as Cruzadas do Rosário nas Filipinas. O sucesso nas Filipinas foi tão grande que o Padre Patrick Peyton retornou para lá diversas vezes.

O projeto das Cruzadas do Rosário em Família para a América Latina cresceu de forma rápida depois que Peter Grace envolveu-se integralmente nele, em 1958, e passou a intermediar as relações com a CIA para conseguir o financiamento desejado. Embora não se tenha abordado aqui a relação entre a guerra civil, o General Franco e o financiamento do governo espanhol à Cruzada do Rosário em Madrid e nas Filipinas, é mister à historiografia fazê-lo. Na década de 1960, com o acirramento da Guerra Fria após a Revolução Cubana, os EUA passaram a ver na ditadura de Franco um aliado na Confederação Anticomunista, pois o governo espanhol se afastara dos falangistas e se apoiava ainda mais na direita católica. As constantes visitas de Patrick Peyton à Espanha e às Filipinas, com patrocínio do governo de Franco, são indícios dessa relação.

No contexto histórico desses acontecimentos, o fantasma do Comunismo era tão temido, que qualquer ação que pudesse ajudar a exorcizá-lo foi considerado não só um 
dever patriótico dos cidadãos dos EUA, mas um ato de devoção católica. Combater o Comunismo foi algo necessário naquele contexto tanto para a Igreja como para o Estado. Para a Igreja Católica, era importante eliminar uma fonte de ateísmo. Já para a política internacional dos EUA, ao eliminar o perigo do Comunismo, seria como remover um obstáculo para a economia e a democracia liberal-capitalista. Talvez Peyton tenha percebido que as Cruzadas do Rosário em Família tinham a capacidade de ajudar a eliminar o Comunismo e, simultaneamente converter pessoas ao Catolicismo, através da oração do Rosário, um símbolo de identidade exclusivamente católico.

John Kennedy foi o primeiro presidente católico dos EUA e, em um país predominantemente protestante, adotar o discurso oficial do Estado era uma forma de o Catolicismo ganhar visibilidade. O discurso oficial do Estado era o combate ao Comunismo e, aos católicos, especialmente a Patrick Peyton, compartilhar dos inimigos do Estado os fariam mais importantes socialmente. A partir de 1960, especialmente após a Revolução Cubana, o alvo do combate ao Comunismo foi a América Latina e Peyton, por sugestão de Peter Grace, voltou seus esforços para o continente, conseguindo dinheiro da CIA para o empreendimento.

Em vários países, especialmente no Brasil, a Cruzada do Rosário em Família coincidiu com golpes civil-militares que afastaram o temor das supostas Revoluções Comunistas em marcha. Muitos desses governos foram consolidados com apoio e dinheiro dos EUA, como a Operação Lincoln Gordon, no Brasil. Embora não disponhamos de fontes que 'comprovem' que o financiamento do governo dos EUA às Cruzadas do Rosário em Família na América Latina visava proteger os aliados, seria ingênuo negar que as autoridades dos países latino-americanos acreditavam que as jornadas de Patrick Peyton eram uma arma eficaz na luta para eliminar o Comunismo da América Latina.

Nos demais países americanos, o financiamento das Cruzadas do Rosário pela CIA e pelos EUA, assim como a recepção delas pelos governos das nações latinas, demonstram a inconsistência da separação entre Igreja e Estado. Na tabela abaixo observamos a proximidade temporal da realização das Cruzadas do Rosário com o ano dos golpes de Estado e/ou ditaduras instaladas nos países latino-americanos. Em alguns deles, as ações do Padre Patrick Peyton antecederam ditaduras ou golpes de Estado, em outros países, as Cruzadas do Rosário chegaram após os eventos políticos, auxiliando na consolidação dos governos ditatoriais. 


\begin{tabular}{|c|c|c|}
\hline País & Ano da Cruzada & Golpe de Estado \\
\hline Paraguai & Não houve & 1954 \\
\hline Colômbia & 1962 & $1953-54$ \\
\hline Venezuela & Não houve & $1964-1958$ \\
\hline Brasil & $1962-1965$ & 1976 \\
\hline Argentina & 1980 & 1966 \\
\hline Bolívia & 1980 & 1973 \\
\hline Chile & $1959-1960$ & 1963 \\
\hline Uruguai & Não houve & 1968 \\
\hline Rep. Dominicana & 1965 & 1963 e 1972 \\
\hline Panamá & 1965 & 1960 e 1979 \\
\hline Equador & 1965 & 1971 \\
\hline El Salvador & 1963 & \\
\hline
\end{tabular}

Peter Grace é um dos personagens históricos desta pesquisa que carrega sobre si a culminância dessas relações: americano leal e católico fiel, desejando a queda do Comunismo por razões religiosas e patrióticas, porém sendo, o maior beneficiado em eliminar a "Ameaça Vermelha ao gerenciar negócios e empreendimentos familiares significativamente históricos na América do Sul.

Em São Paulo, os preparativos para a Cruzada foram iniciados em fevereiro de 1964 e a realização da Grande Concentração ocorreu após o golpe civil-militar, em agosto. A Marcha da Família com Deus pela Liberdade aconteceu antes e durante da preparação e da divulgação da Cruzada do Rosário em Família. Muitas donas de casa, que eram militantes anticomunistas da CAMDE, identificaram-se facilmente com Patrick Peyton, tornando-se voluntárias da Cruzada. As Marchas da Família com Deus pela Liberdade foram a antecipação da Grande Concentração da Cruzada do Rosário.

Enquanto limitações do alcance da presente pesquisa, apontamos, além da relação das Cruzadas do Rosário com o General Franco e a Guerra Civil espanhola, não alcançamos fazer uma comparação com a realização das Cruzadas do Rosário no Chile e outros países latino-americanos. Há outros aspectos a ampliar nessa temática, tais como o mapeamento e a análise acerca dos padres e bispos que acompanharam Patrick Peyton no Brasil, e as diferentes posições ocupadas por eles, especialmente no Rio de Janeiro e em São Paulo, quanto ao progressismo ou conservadorismo católico. Outro aspecto, que, 
por motivos limitadores, não foi abordado, foi a análise do material midiático produzido pela Family Theater Productions, a produtora de filmes fundada pelo padre. É pertinente um levantamento das principais produções e buscar analises do conteúdo dos filmes, das fontes financiadoras, dos atores envolvidos e de outros aspectos que vinculam o Peyton à propaganda política dos EUA no contexto da Guerra Fria.

Consideramos que a realização das Cruzadas do Rosário em Família no Brasil não estava permeada apenas de motivações religiosas de divulgação da Oração do Rosário e da união das famílias, e sim, por um discurso anticomunista indireto e subjacente. Por sua vez, a Igreja Católica, como em outros tempos, estava dividida entre os grupos renovadores e os conservadores. Patrick Peyton conseguiu agregar grande parte dos líderes religiosos dos dois grupos em torno do Rosário, um símbolo de identidade aceito em todos os segmentos católicos. Patrocinado pelos anticomunistas, Peyton evitou a utilização desse termo em seus discursos e se limitou a promover argumentos como a união da família em torno do Rosário, evitando ataques ideológicos abertos, agregando, assim, o número máximo de seguidores, uma característica de sua maneira peculiar de promover o anticomunismo.

\section{REFERÊNCIAS}

ARNOLD, Jeanne Gosselin. A Man of Faith - Father Patrick Peyton, C.S.C., his life, mission and message. Hollywood, California: Family Theater, Inc. 1983.

CALDEIRA, Rodrigo Coppe. Um bispo no Concípio Vaticano II. Dom Geraldo de Proença Sigaud e o Coetus Internacionalis Patrum. Revista Eclesiástica Brasileira, v.71, n.282.

CALDEIRA, Rodrigo Coppe. Um bispo no Concípio Vaticano II. Dom Geraldo de Proença Sigaud e o Coetus Internacionalis Patrum. Revista Eclesiástica Brasileira, v.71, n.282.

GOMES, Gabriela. El anticomunismo de la juventude conservadora chilena. Es caso de la falange nacional (1935-1957). Dossiê - Pensamento de direita e chauvinismo na América Latina. Mediações, Londrina. v.19. n.1, p.170-186, 2014.

GUISOLPHI, Anderson José. As Cruzadas do Rosário em Família e a atuação anticomunista do Padre Patrick Peyton no Brasil (1962-1964). (Dissertação). Programa de Pós-Graduação em História/PPGH. Universidade de Passo Fundo - UPF, 2013. 
GRIBBLE, Richard. Anti-communism, Patrick Peyton, CSC and the C.I.A. Journal of Church and State, v. 45,n. 3, 2003, p.535-558.

MOTTA, Rodrigo Patto Sá. Em guarda contra o "Perigo Vermelho": o anticomunismo no Brasil (1917-1964). São Paulo: Perspectiva: FAPESP, 2002.

NEW YORK TIMES - New York; 21/04/1995; Obituary. Disponívelem: http://www.nytimes.com/1995/04/21/obituaries/j-peter-grace-ex-company-chief-dies-at81.html?pagewanted $=$ all\&src=pm. Acessado em 15/08/2012.

O ANHANGABAÚ foi o cenário da maior manifestação de fé já vista na capital. O Estado de S. Paulo, 18/08/1964 p. 14-15.

O ESTADO de S. Paulo. 08/12/1962 p.06; 11/12/1962 p.25; 12/12/1962 p.15; 16/12/1962 p. 7; 18/12/1962 p. 5;21/12/1962 p. 6.

PEYTON, Patrick, C.S.C. All for Her: The Autobiography of Father Patrick Peyton, C.S.C. Hollywood, California: Family Theater Publications, 1967.

PEREIRA, Marco Antônio Machado Lima. "Guardai-vos dos falsos profetas": matrizes do anticomunismo católico (1935-1937). Franca (SP): UNESP, 2010. Dissertação.

RODEGHERO, Carla Simone. Memórias e avaliações: Norte-americanos, católicos e a recepção do anticomunismo brasileiro entre 1945 e 1964. (Tese) Porto Alegre: UFRGS, 2002.

RODEGHERO, Carla Simone. O diabo é vermelho: imaginário anticomunista e Igreja Católica no Rio Grande do Sul (1945-1964). - 2. ed. - Passo Fundo (RS): UPF, 2003.

RODEGHERO, Carla Simone. Religião e patriotismo: o anticomunismo católico nos Estados Unidos e no Brasil nos anos da Guerra Fria. In: Revista Brasileira de História. São Paulo, v.22, n 44, p. 463-488. 2002.

SILVA, Vicente Gil da. A Aliança para o Progresso no Brasil: de Propaganda Anticomunista à Instrumento de Intervenção Política (1961-1964). (Dissertação). UFRGS, 2008.

RODEGHERO, Carla Simone. Memórias e avaliações: norte-americanos, católicos e a recepção do anticomunismo brasileiro entre 1946 e 1964. (Tese). Porto Alegre: UFRGS, 2002.

VIZENTINI, Paulo Fagundes. A Guerra Fria (1947-1987): conflito ou sistema? Revista

História: Debates e Tendências - v.6. n.2. Passo Fundo (RS): UPF/PPGH, 2008, 